\title{
"DOLORACIÓN DE VOS COMO CLAUSURA": EXPRESIÓN DEL DOLOR Y REESCRITURA SANJUANISTA EN CARTA ABIERTA, DE JUAN GELMAN
}

En su reflexión acerca de la "filialidad"1, Emmanuel Lévinas define la paternidad como una salida de la "clausura de la identidad"2, que inaugura una trascendencia "frente a la existencia propia", que abre al sujeto a un "existir pluralista" . El poeta argentino Juan Gelman (1930) da un testimonio desgarrador de esta trascendencia sui generis en Carta abierta (1980). Gelman dedica este poemario "a [su] hijo", secuestrado por un comando military "desaparecido" en 1976 junto con su mujer, embarazada ${ }^{4}$. La alteridad singular del hijo que, según Lévinas, abre para el padre "un porvenir más allá de mi propio ser"5, tiende aquí a invertirse: el poeta tiene que explorar este tiempo clausurado por la muerte del hijo. Éste le precede en el orden de una temporalidad finita abocada a la muerte de tal manera que el poeta llega a poner en tela de juicio la relación "natural" de engendramiento: “‘acaso no te soy para padrearte? /...realidad que sufrís como pariendo"6.

La expresión del doble sufrimiento del hijo y del padre es uno de los hilos conductores del libro. Sin embargo, a pesar de echar sus raíces en un acontecimiento concreto de la vida del autor, la expresión del dolor no es una temática nueva en la poesía de Gelman. Al

1 "L'amour et la filiation", Ethique et infini. (Dialogues avec Philippe Nemo), Librairie Arthème Fayard-Radio-France, Paris, 1982, pp. 55-65. La palabra "filialidad" traduce el término francés "filialité".

2 "Le fait de voir les possibilités de l'autre comme vos propres possibilités, de pouvoir sortir de la clôture de votre identité et de ce qui vous est imparti vers quelque chose qui ne vous est pas imparti et qui est cependant de vous -voilà la paternité" (ibid., p.63).

3 Ibid., p. 65.

${ }^{4}$ Cf. el post scriptum al final del poemario. Recordemos que Carta abierta se publicó en Si dulcemente, Lumen, Barcelona, 1980, pp. 43-73. En este libro se encuentran también Notas (pp. 9-42) y Si dulcemente (pp. 75-105). Nos basamos en la edición siguiente: Carta abierta en de palabra, Visor, Madrid, 1994, pp. 125-155.

${ }^{5}$ E. LÉvinAs, op. cit., p. 63.

${ }^{6}$ Poema X, op. cit., p. 139. 
contrario, se trata de una de las constantes que se pueden rastrear en el conjunto de su vasta obra ${ }^{7}$. Según Jaime Giordano, los poemarios del principio de la década de los años ochenta ${ }^{8}$ presentan una "reconcentración del dolor", y algo que empieza a parecerse a una verdadera "sabiduría". En Citas y Comentarios $(1982)^{9}$, por ejemplo, los "poemas resumen la presencia y el dolor desde todos los ángulos de la memoria y la percepción, en una escritura dislocada y conflictiva"10. Miguel Gomes confirma, amplía y actualiza la lectura de Giordano al definir la estética gelmaneana como un "expresionismo patológico":

El expresionismo de Gelman... es "patológico", no por ser enfermizo, sino por responder a un sujeto lírico empeñado en conmocionar, en manifestarse menos a través de la dignidad del ethos que a través de los afectos y las pasiones. Ésta es, a mi modo de ver, la vía elegida en la totalidad de su poesia ${ }^{11}$.

Si bien es representativa del conjunto de la obra, es de notar que Carta abierta es uno de los lugares donde este "expresionismo" de "los afectos y las pasiones" recibe un tratamien to de mayor intensidad. Este poemario, escrito en el exilio en 1980, es, según Daniel Freidemberg, "una de las más arduas, hondas y lúcidas indagaciones en el dolor que presenta la poesía de todos los tiempos"12. Para llevar a cabo esta indagación, el poeta despliega e intensifica todos los recursos expresivos ya característicos de su poesía anterior: la desarticulación sintáctica, la creación de neologismos audaces y muy significativos, el ritmo quebrado que se amolda al flujo de las emociones, la oralidad que se asienta en un tono, un ritmo, un léxico, una morfosintaxis peculiares y el trabajo intertextual. Este último recurso cobra una importancia especial en varios libros de los años ochenta, sobre todo en Citas y Comentarios y Com/posiciones, poemarios cuyos títulos ya hacen hincapié en la intertextualidad. En Carta abierta, el paratexto, centrado en las circunstancias externas de la escritura, no evidencia ninguna clave de

${ }^{7}$ La importancia de la obra de Juan Gelman es un hecho cada vez más establecido. En 1997, J. Gelman recibió el Premio Nacional de Poesía 1994-1997 por Salarios del impio. En noviembre de 2000 le fue otorgado el Premio de Literatura Latinoamericana y del Caribe Juan Rulfo; en el 2004, el Premio Iberoamericano de Poesía Ramón López Velarde y, en 2005, el Premio Reina Sofía de Poesía Iberoamericana.

${ }^{8}$ Jaime Giondano no cita Carta abierta; se refiere principalmente a Hechos y relaciones (1980) y Citas y Comentarios ("Juan Gelman o el dolor de los otros", Inti, 1984, núms. 18/19, 169-190).

${ }^{9}$ Se trata de dos libros publicados como un conjunto en la primera edición (Visor, Madrid, 1982), pero que luego aparecen como dos entidades distintas (como consta, por ejemplo, en su inclusión en de palabra).

$10 \mathrm{~J}$. Giordano, op. cit., p. 179.

11 "Juan Gelman en la historia de la poesía hispanoamericana reciente: neorromanticismo y neoexpresionismo", Revlb, 1997, núm. 181, p. 658.

12 "Libro por libro", La Maga, 1997, núm. 28, p. 38. 
tipo intertextual. Al contrario del libro casi contemporáneo ${ }^{13}$, Citas y Comentarios, los títulos de los poemas de Carta abierta se reducen a una mera numeración romanal4. Sin embargo, otras voces, otros textos asoman y dan a esta "indagación en el dolor" su tonalidad inconfundible. ¿De dónde vienen esas voces? ¿Se puede vislumbrar una organización significativa en el entramado textual que configuran?

Un análisis del primer poema proporciona las claves de lectura que nos permitirán desentrañar las modalidades textuales e intertextuales de la "indagación en el dolor" que se despliega en los vein ticuatro poemas restantes. Los dos primeros versos del poema abren un espacio indeciso, vacilante, alrededor del dolor:

\section{hablarte o deshablarte/dolor mío/ manera de tenerte/destenerte/}

Esta vacilación está enmarcada en los dos dobletes de infinitivos construidos de la misma manera: infinitivo-te/ des-infinitivo-te. "Deshablarte" y "destenerte" son dos entre los numerosos neologismos de la obra. Un análisis global permite aislar 55 neologismos entre los cuales veinte están formados con el prefijo des-15, lo que contribuye a colocar el lenguaje del poemario bajo el signo de la carencia. Mientras que "hablarte" funda la existencia del poemario, "deshablarte", con su matiz de inversión y negación, la pone en tela de juicio nada más abierto el libro. El segundo doblete, si bien es un eco del primero, introduce una pequeña variante al borrar la conjunción "o" y sustituirla por una barra que puede significar la disyunción excluyente o, al contrario, la voluntad de no zanjar. En otros términos, la palabra "hablada" o"deshablada" podría ser a la vez una manera de "tenerte" (recordarte, hacerte vivo) y "destenerte" (aceptar el duelo y la pérdida irremediable). En el espacio abierto por esta tensión se mueve el poemario no de manera lineal sino en "espiral" 16 , volviendo y ahondando obsesivamente en el mismo punto, en pos de ese lugar en el cual se aunarían los términos opuestos.

13 Véase la nota 43.

${ }^{14}$ Recordemos que los títulos de los poemas de Citas y Comentarios incluyen la mención entre paréntesis del autor 'citado' y/o 'comentado' en el texto que encabezan (san Juan de la Cruz, santa Teresa, Hadewijch, Ezequiel, Rey David, etc.)

${ }^{15}$ Se trata de los neologismos siguientes (con la mención del poema en el que aparecen): desabuenándose (X), desalmadura (VII), desapartando (XIX), desapenando (I), (te) descriaturás (X), desdoler (XVIII), desfieraba (XIV), desfuéramos (III), desfuiste (III), desfuera (XXIV), deshablar(te) (I), deshijar (VII), desmorirte (IV-XXIV), desniñar (IX), despadecerme (V), despadra (V), despajaritarse (XV), desperseveran (XVIII), desquerer (V), destener (I), destrabajo (XXIII), desvuelo (XXIII).

16 Cf. el análisis de NÊsTOR PONCE, quien habla de "escritura en espiral" ("La "nota XXII» de Juan Gelman y un soneto de Quevedo", en Réceptions et réélaborations sociales, culturelles et linguistiques aux $\mathrm{xIX}^{e}$ et $\mathrm{xX}^{e}$ siècles. Actes du Colloque ALMOREAL, Angers, 1992, p. 53). 
La sintaxis y el ritmo refuerzan esta construcción en espiral. El poema consta de ocho estrofas de cuatro versos sin rimas regulares. Los encabalgamientos son frecuentes, especialmente de una estrofa a otra. El texto se presenta como una sucesión inconexa de frases nominales, muchas de ellas con oraciones relativas. Los sustantivos nucleares de estos sintagmas esbozan el espacio intersubjetivo donde se mueve el poema: pasión, hijo, paredes, alma, recordación, alma, hijito, aire, agüitas, rostro, hijo, pedazo, amigo, amor, sangre, cielo. La categoría del sustantivo no sólo es la más frecuente, sino que tiende a absorber las otras categorías ${ }^{17}$, ya que se sustantivan verbos ${ }^{18}$ o conjunciones ${ }^{19}$. De ahí que resaltan los infinitivos del incipit (ya citados) y del final del poema:

$$
\begin{aligned}
& \text { besar con besos de la boca/o } \\
& \text { cielo que abrís hijando tu morida }
\end{aligned}
$$

El verbo "besar" -no sustantivado- no sólo constituye el punto culminante de toda la red semántica que gira alrededor del afecto paterno (el "amor derramadísimo", vv. 27-28), sino que también evoca claramente el versículo bíblico que abre el Cantar de los Cantares: "iOh si él me besara con besos de su boca!" $(I, 2)^{20}$. Nos encontramos aquí frente a una cita casi literal de la Biblia, lo que nos permite hablar de intertexto, concebido éste como "el o los texto(s) que un texto determinado reescribe"21.

El intertexto bíblico remite a su vez a otro: en el seno de la tradición hispánica, ¿cómo no percibir el Cantar a través de su relectura por parte de los místicos castellanos? Esta presencia latente de los místicos de hecho se ha sugerido en la segunda estrofa del poema al

17 Notemos que también hay un caso de transformación de un sustantivo en adjetivo: "astrísimo", v. 23.

${ }^{18}$ En esos sintagmas hay numerosos verbos sustantivados (por ejemplo, "tu mirar", v. 19; "del acabar temprano", v. 22; "mi propio volar", vv. 28-29; "el siendo", v. 9; "el no avisado"; v. 27).

${ }^{19}$ Cf. "el mientras", v. 9.

${ }^{20}$ Según La Santa Biblia, Sociedades Bỉblicas en América Latina, 1960, p. 646.

${ }^{21}$ Esta es la definición que da Nathalie Piégay-Gros en su síntesis crítica de las principales teorías acerca de la intertextualidad desarrolladas por G. Genette, M. Riffaterre y R. Barthes (Introduction à l'intertextualité, Dunod, Paris, 1996, pp. 7-10). Veremos más adelante que esta definición centrada en la reescritura es muy pertinente al definir el funcionamiento del texto de Gelman (cf. nota 28). Esta definición amplia del intertexto plantea el delicado problema de las fronteras de la intertextualidad. En esta perspectiva, nos parece pertinente la observación de LAURENT JENNY: "nous proposons de parler d'intertextualité seulement lorsqu'on est en mesure de repérer dans un texte des éléments structurés antérieurement à lui, au-delà du lexème, cela s'entend, mais quel que soit leur niveau de structuration" ("La stratégie de la forme", Poétique, 1976, núm. 27, p. 262). 
evocar la ausencia del hijo en términos propios de los tratados sobre la vida ascética y mística:

$$
\begin{aligned}
& \text { hijo que vuela por quietudes/por } \\
& \text { arrobamientos/voces/sequedades/ } \\
& \text { levantamientos de la ser/... } \\
& \text { (vv. 4-6). }
\end{aligned}
$$

Es interesante subrayar el hecho de que el intertexto presente aquí remite a la escritura en prosa: éste es un rasgo fundamental que el estudio del resto del poemario comprobará. Además, el motivo del vuelo del hijo, presente en la primera estrofa del poema, encuentra un eco en un lugar simétrico22 ("mi propio//volar de vos a vos", vv. 2829), como si toda la evocación anterior permitiera precisamente una comunicación bajo el signo del "vuelo". De hecho, el hijo se sitúa en la esfera celestial ("rostro o noche/ / donde brillás astrísimo de vos", vv. 22-23), lo que confirma el último verso: "cielo que abrís hijando tu morida" (v. 32). El neologismo "hijando"23 tiene otra ocurrencia en el poema donde el YO (o sea el padre) es sujeto del verbo: "hijo que hijé contra la lloradera" (v. 24). En el verso 32 en cambio, es el hijo quien engendra... la muerte. Al duelo como proceso evocado al principio ("tenerte/destenerte") corresponde esta entrada en la muerte como apertura, lo que invierte la relación de engendramiento.

El primer poema, el más largo de la colección, reúne las pautas temáticas así como la mayoría de los recursos expresivos que se van a profundizar y enriquecer en el resto del poemario: no sólo la exploración del doloroso "hijar" tanto del padre como del hijo constituye el tema fundamental del poemario, sino que también el intertexto místico que apenas aflora en el primer poema vuelve a hacer escuchar su voz en otros textos.

Antes de desarrollar un análisis sistemático es preciso recordar que el descubrimiento de un intertexto implícito (es decir, no designado como tal en el texto) depende del lector, de manera que los resultados que vamos a exponer a continuación no pretenden ser exhaustivos. Sin embargo, tal y como consta más adelante, constituyen un conjunto coherente que apunta a un intertexto dotado de una articulación y una significación que quedan por analizar.

En efecto, hemos podido rastrear la presencia significativa de un nutrido intertexto sanjuanista en un bloque determinado de poemas:

22 Al cuarto verso ("hijo que vuela") responde el cuarto verso antes del final ("volar de vos a vos", v. 29).

${ }^{23}$ Se encuentra también esta palabra en la obra de CÉsar VAllejo, por ejemplo en Trilce, XIII: "Pienso en tu sexo.// Simplificado el corazón, pienso en tu sexo,// ante el hijar maduro del día" (Obra poética completa, ed. E. Ballón Aguirre, Biblioteca Ayacucho, Caracas, 1985 , p. 60). 
del XIII al XIX, se multiplican las alusiones al Cántico espiritual de san Juan de la Cruz, tanto en su versión poética como en el comentario en prosa. Estas alusiones remiten a su vez a la fuente principal de san Juan de la Cruz: el Cantar de los Cantares. Veamos paso a paso cómo se despliega esta red intertextual.

En la última estrofa del poema XIII aparece un eco del Cantar de los Cantares:

por arrabales/plazas donde busco ¿quedo pensando porque no te hallé?

(wv. 13-14)

Por las calles y por las plazas, buscaré al que ama mi alma.

Busquéle y no le hallé

(Ct 3, 2).

El escenario (la ciudad), las acciones (buscar y no hallar) y el tono (ansia llena de amor) se repiten casi textualmente en uno y otro texto. Sin embargo, la modalidad (interrogativa en Gelman) introduce un cambio. Asimismo, la primera estrofa del mismo poema XIII parece constituir un eco del Cántico espiritual de san Juan de la Cruz: la interrogación "¿dónde estás escondido?", la mención del "gemido" y de la "herida" remiten a la primera estrofa del famoso poema del carmelita:

¿Adónde te escondiste,

Amado, y me dejaste con gemido?

Como el ciervo huiste,

habiéndome herido;

salí tras ti clamando, y eras ido ${ }^{24}$.

Se podría objetar que estos son indicios demasiado leves y dispersos como para poder asegurar una in tertextualidad "fuerte"25. Sin embargo, si tomamos en consideración el comentario en prosa de estos mismos versos, las alusiones se intensifican de manera sorprendente:

\begin{tabular}{|c|c|}
\hline Poema XIII (Gelman) & Intertexto ${ }^{26}$ \\
\hline $\begin{array}{l}\text { dentro de mi el gemido tengo como// } \\
\text { (v. 4) }\end{array}$ & $\begin{array}{l}\text { Nosotros dentro de nosotros tenemos } \\
\text { el gemido, esperando la adopción y } \\
\text { posesión de hijos de Dios (san Pablo, } \\
\text { citado en el } C E \text {, prosa, 1, p. } 444 \text { ). }\end{array}$ \\
\hline $\begin{array}{l}24 \text { SAN JUAN DE LA CRUz, Cántico espiri } \\
\text { Iglesia, BAC, Madrid, 1982, p. } 436 \text {. } \\
{ }^{25} \text { L. JENNY (op. cit., pp. 262-264) distir } \\
\text { do la alusión es un préstamo reconocible } \\
\text { mente dicha, es decir fuerte (cf. supra). } \\
{ }_{26} \text { Las siglas remiten a las fuentes sigu }\end{array}$ & $\begin{array}{l}\text { ual (A), Obras completas, ed. L. Ruano de la } \\
\text { pue entre la intertextualidad débil (cuan- } \\
\text { pero aislado) y la intertextualidad propia- }\end{array}$ \\
\hline
\end{tabular}




\begin{tabular}{|c|c|}
\hline Poema XIII (Gelman) & Intertexto \\
\hline $\begin{array}{l}\text { desolación de vos/ausencia herida/ } \\
/ / \text { seca/sola de vos... (v. 5-6) }\end{array}$ & $\begin{array}{l}\text { Este, pues, es el gemido que el alma } \\
\text { tiene siempre en el sentimiento de la } \\
\text { ausencia de su Amado, mayormente } \\
\text { cuando, habiendo gustado alguna } \\
\text { dulce y sabrosa comunicación suya, } \\
\text { la dejó seca y sola (loc. cit.). }\end{array}$ \\
\hline $\begin{array}{l}\text {... salgo de todas // } \\
\text { las cosas para verte/odiandomé// } \\
\text { (w. } 7-8 \text { ) }\end{array}$ & $\begin{array}{l}\text { Y es de saber que este "salir" se } \\
\text { entiende de dos maneras: la una, } \\
\text { saliendo de todas las cosas, lo cual se } \\
\text { hace por desprecioyaborrecimiento } \\
\text { dellas; la otra, saliendo de sí misma } \\
\text { por olvido y descuido de sí, lo cual } \\
\text { se hace por aborrecimiento santo de } \\
\text { sí misma en amor de Dios... ( } C E \text {, } \\
\text { prosa, } 1 \text {, p. 446). }\end{array}$ \\
\hline
\end{tabular}

toque sacándome de mí/hijo mío ...¿pueda yo desasirme de mí para ya asirte (vv. 10-12)

por arrabales/plazas donde busco? ¿quedo pensando porque no te

[hallé? (vv. 13-14)

¿gano tu pérdida para perderme? (v. 15)
Esposo mío, en aquel toque tuyo y herida de amor sacásteme no sólo de todas las cosas... mas también me hiciste salir de mí... y levantásteme a ti clamando por ti, desasida ya de todo para asirme a $t i$ (loc. cit.).

por los arrabales y las plazas buscaré al que ama mi ánima; busquéle y no le hallé. (Cantar 3, 2 citado por san Juan en loe. cit.).

habiéndose ya perdido de amor por Dios, no ha hallado la ganancia de su pérdida, pues carece de la dicha posesión de el Amado, porque él se perdió ( $C E$, prosa, 1, pp. 446-447).

de la Cruz (versión A, cit. supra, n. 24). Para el comentario en prosa, mencionamos la canción y la página; para la poesía, indicamos la canción y los versos. La mención Cantar remite al Cantar de los Cantares; las cursivas son mías. Cae fuera del propósito de este artículo justificar ampliamente la elección de la versión $\mathrm{A}$, cuya autenticidad es aceptada por todos (al respecto véase, especialmente, la argumentación de Max Huot de Lonchamp, Lectures de Juan de la Croix. Essai d'anthropologie mystique, Beauchesne, Paris, 1981, pp. 417-420). Para una opinión contraria se puede citar a Domingo YNDURárn, "La preferencia por CB es, en cierto modo, arbitraria ya que hubiera podido lo mismo elegir CA o CA..." (en su ed. a las Poesias de san Juan de la Cruz, Cátedra, Madrid, 1995, p. 231). 
Las correspondencias saltan a la vista. En general, se conserva la misma palabra ${ }^{27}$, pero a veces introduciendo modificaciones en cuanto a la persona o el tiempo del verbo. En otras alusiones, aparece la misma raíz léxica, pero de otra categoría morfológica (paso de un sustantivo a un verbo). De manera más general, el poema gelmaneano aparece a la luz del intertexto como una verdadera reescritura $^{28}$ del texto sanjuanista. No sólo retoma sintagmas aislados, situaciones o sentimientos de actantes caracterizados de manera semejante (el alma en ansia de amores $w s$. el amado ausente), sino que enlaza estos rasgos en una continuidad que respeta las articulaciones del comentario en prosa, pero modifica la significación del proceso en cuestión. La necesaria purificación que sólo posibilita la unión humano-divina en san Juan de la Cruz se desliza, en el poema de Gelman, hacia un camino nocturno en el que es el hijo quien ocupa el lugar del Dios, a la vez ausente y presente, de los místicos cristianos. La modalidad afirmativa sanjuanista da paso a un tono preferentemente interrogativo; el ansia de reencuentro es aquí una esperanza sin otro fundamento que uri deseo dispuesto a todo, incluso a la locura29: “¿desalmándome llegue a tu almitar?" (v. 16). Este último verso se cierra con un neologismo muy hermoso, en el cual se puede leer una conjunción de "alma" y de "altar", como si el único lugar sagrado para el poeta fuese el alma de su hijo, que intenta alcanzar gracias a una voz poética marcada por la alteridad.

El poema XIV confirma la presencia sanjuanista, intensificando las alusiones a la prosa. La continuidad esbozada en el poema XIII se refuerza en el XIV ya que remite al comentario de la segunda estrofa del Cántico espiritual y, sobre todo, del quinto verso (no mencionado

27 Subrayemos el caso significativo de la palabra "arrabal". Según Jorce BoCCANERA, "arrabal" forma parte de esos "términos... que enlazan aún más la voz de Gelman a la súplica del san Juan de la Cruz del Cántico espiritualy a santa Teresa en los Versos nacidos del fuego del amor de Dios" (Confiar en el misterio. Viaje por la poesía de Juan Gelman, Sudamericana, Buenos Aires, 1994, p. 197). Este comentario de Boccanera versa sobre Citas y Comentarios, que considera como el punto de partida de una exploración más "concentrada" de la Biblia y de los místicos castellanos (op. cit., p.195), pasando por alto la intensa presencia sanjuanista en Carta abierta.

28 Empleamos el término general de "reescritura" ya que ningún otro concepto nos parece adecuado para calificar el funcionamien to textual descrito aquí. La noción de "transposición" (así como todas sus variantes: "transtylisation", "contamination", etc.), definida por GÉrard GenetTe (Palimpsestes. La littérature au second degré, Seuil, Paris, 1982, pp. 237 ss.), oculta el hecho de que hay relaciones de "co-presencia", es decir de intertextualidad en el sentido de Genette, en Carta abierta. La noción de "pastiche" tampoco conviene para Carta abierta que no puede constituir de ninguna manera un "faux intentionnel", según la definición de Pierre Laurette ("A l'ombre du pastiche. La réécriture: automatisme et contingence", Texte, 1983, núm. 2, pp. 115-116).

${ }^{29}$ Es lo que evoca el poema X: "te gelmaneo/te cabalgo como //loco de vos/potro tuyo que pasa" (v. 4-5). 
como tal por Gelman): "Decilde que adolezco, peno y muero" ( $C E$, poesía 2, v. 5). En su comentario, el san to define con precisión los tres dolores enunciados en tono crescendo en la poesía: a cada dolor corresponde una de las tres potencias del alma que sufre de una manera específica la ausencia de Dios. El texto de Gelman menciona estas tres potencias: la voluntad, la memoria, el entendimiento. He aquí la correspondencia precisa entre ambos textos:

Poema XIV (Gelman)
anda pidiendo verte/entendimiento
que pierde sangre como vos/de vos/
voluntad que no mira tu mirada

memoria que amarísima de muere amarillea al pie de tu otoñar/ memoria que moris con cada viva

[recordación
Cántico espiritual

Tres maneras de necesidades representa aquí el alma, conviene a saber: dolencia, pena y muerte, porque el alma que de veras ama, ordinariamente en el sentimiento de la ausencia de Dios padece destas tres maneras dichas, según las tres potencias de la alma, que son: entendimiento, voluntad y memoria. Acerca del entendimiento adolece porque no ve a Dios... Acerca de la voluntad pena porque carece de la posesión de Dios... Acerca de la memoria muere porque, acordándose que carece de todos los bienes de el entendimiento, que es ver a Dios, y de todos los bienes de la voluntad, que es poseerle, y que también es muy posible carecer de Él para siempre, padece en esta memoria a manera de muerte ( $C E$, prosa, 2, p. 449).

El asensio que es yerba amarisima, se refiere a la voluntad... (loc. cit.)

En este caso, el trabajo intertextual es diferente del anterior: Gelman retoma explícitamente la concepción sanjuanista ${ }^{30}$ de las tres potencias del alma. Pero, en lo que a las dos primeras atañe, el paralelismo no va más lejos: la privación de la visión pasa del entendimiento (san Juan) a la voluntad (Gelman). En cambio, Gelman retoma la idea sanjuanista de que el mayor mal afecta la memoria, la cual padece una

30 No es una concepción original. Véase la presentación de "la antropología sanjuanista" por DARío GuTIÉrRez MARTín, quien recuerda que san Juan de la Cruz toma prestada la doctrina de las tres potencias del alma a san Agustín (San Juan de la Cruz. Su personalidad psicológica, Ediciones Paulinas, Ávila, 1990, p. 22). 
suerte de muerte. Gelman desarrolla este punto más que los dos anteriores y aparecen dos referencias a la muerte ("muere", "morís"); el arcaísmo "amarísima", que en san Juan se refiere a la voluntad, remite en Gelman a la memoria ${ }^{31}$. La experiencia del místico permite al escritor argentino expresar con fuerza los estragos de la ausencia en la memoria. Toda la escritura de Gelman, que se alza libro tras libro "contra los perros del olvido" (Nota XXV), encuentra en la prosa de san Juan un lenguaje capaz de traducir intensa y acertadamente lo que está en juego tanto en su vida como en su escritura.

Los poemas XV, XVI y XVII siguen tejiendo ecos del Cántico espiritual. Lo más notable es que continúan respetando el orden del Cántico: el poema XV remite a la canción 3, el XVI a la canción 5, mientras que el XVII remite a las canciones 6 y 7 .

\begin{tabular}{|c|c|}
\hline Gelman & Cántico espiritual \\
\hline $\begin{array}{c}\mathrm{XV} \\
\text { O corazón desnudo/fuerte/libre/ } \\
\text { Rechazador de mundos/flores/ } \\
\text { [dichas/ }\end{array}$ & $\begin{array}{l}\text { ni cogeré las flores, } \\
\text { ni temeré las fieras, } \\
\text { y pasaré los fuertes y fronteras ( } C E \text {, } \\
\text { poesía, } 3 \text {, vv. } 3-5) \text {. }\end{array}$ \\
\hline $\begin{array}{c}\text { XVI } \\
\text { paso de sol a luna/por criaturas } \\
\text { como pruebas de vos/que habrás } \\
\text { [ mirado } \\
\text { mucho/ ya que andan por aquí } \\
\text { [vestidas } \\
\text { devos/o sea hermosas/ tiernas } \\
\text { [como... }\end{array}$ & $\begin{array}{l}\text { pasó por estos sotos con presura } \\
\text { e, yéndolos mirando, } \\
\text { con sola su figura } \\
\text { vestidos los dejó de hermosura }(C E \text {, } \\
\text { poesía, } 5 \text {, vv. } 1-4)\end{array}$ \\
\hline $\begin{array}{c}\text { XVII } \\
\text { no quiero otra noticia sino vos/ }\end{array}$ & $\begin{array}{l}\text { Como ve no hay cosa que la pueda } \\
\text { curar su dolencia sino la vista y la } \\
\text { presencia de su Amado, desconfiada } \\
\text { de otro cualquiera remedio, pídele } \\
\text { en esta canción [6] la entrega y } \\
\text { posesión de su presencia diciendo } \\
\text { que no quiera de hoy más entretenerla } \\
\text { con otras cualesquier noticias y comuni- } \\
\text { caciones suyas, porque no satisfacen } \\
\text { a su deseo y voluntad... (CE, prosa, } \\
6 \text {, p. } 458 \text { ). }\end{array}$ \\
\hline
\end{tabular}

31 En otro artículo hemos desarrollado el tratamiento del tema de la memoria por parte de Gelman en varias de sus obras (G. FABRY, "Las noches de la memoria en la poesía de Juan Gelman", Trilce, diciembre de 2001-abril de 2002, núm. 8, 13-30). 


\begin{tabular}{|c|c|}
\hline Gelman & Cántico espiritual \\
\hline $\begin{array}{l}\text { cualquiera otra es migajita donde } \\
\text { se muere de hambre la memoria/... }\end{array}$ & $\begin{array}{l}\text { porque todas las demás cosas no so- } \\
\text { lamente no la satisfacen, mas antes, } \\
\text { como habemos dicho, la hacen } \\
\text { crecer la hambre y apetito de verle a } \\
\text { Él como es, y así cada visita que de } \\
\text { el Amado recibe de conocimiento, } \\
\text { o sentimiento, o otra cualquiera } \\
\text { comunicación: los cuales son como } \\
\text { mensajeros que dan a la alma re- } \\
\text { caudos de noticias de quien Él es, } \\
\text { aumentándole y despertándole más } \\
\text { el apetito, así como hacen las mea- } \\
\text { jas en grande hambre (CE, prosa, } 6 \text {, } \\
\text { pp. 458-459) }\end{array}$ \\
\hline $\begin{array}{l}\text {...no acabo de acabar/ } \\
\text { es claramente entiendo que no } \\
\text { [entiendo }\end{array}$ & $\begin{array}{l}\text { en aquel sentir siente tan alto de } \\
\text { Dios, que entiende claro se queda el } \\
\text { todo por entender; y aquel entender } \\
\text { y sentir tan inmensa la Divinidad, que } \\
\text { no se puede entender acabadamente } \\
(C E \text {, prosa, } 7, \text { p. } 462) \text {. }\end{array}$ \\
\hline
\end{tabular}

Los ecos sanjuanistas de los poemas XV y XVI son relativamente sutiles, pero en el poema siguiente se van reforzando. En este último caso, Gelman tiene tendencia no a hilar citas, sino más bien a resumir con alguna fórmula sintética las largas disquisiciones de san Juan. Gelman vuelve a hacer hincapié en el dolor de la memoria que se muere de hambre en la ausencia del hijo, que "cava para seguir buscándote / se vuelve loca de oscuridad" (vv. 3-5). Las sensaciones traducen de manera corpórea la experiencia de muerte por la que pasa ("sudo de frío", v. 9; "helado de amor yago", v. 10): el lenguaje de Gelman se enlaza sin solución de continuidad con el de san Juan en estas expresiones oximorónicas tan próximas a las del santo. El poema se cierra con una alusión al entendimiento cegado, tema central de la travesía de la "noche oscura", cuyas etapas principales san Juan de la Cruz vuelve a exponer en la primera parte del Cántico espiritual.

El poema XVIII sigue hilando sus lazos con el Cántico espiritual, tanto el discurso en verso como en prosa. Aunque se puede vislumbrar una alusión a las canciones 4 y 5 , se respeta globalmente el orden de las canciones, ya que la mayor parte del intertexto pertenece a las canciones 7,8 y 9 : 


\begin{tabular}{ll}
\hline \multicolumn{1}{c}{ Poema XVII (Gelman) } & \multicolumn{1}{c}{ Cántico espiritual } \\
\hline balbucean criaturas (v. 2) & un no sé qué que quedan balbuciendo \\
& [las criaturas] (CE, poesía, 7, v. 5). \\
hablan niñando (v. 4) & Por eso dice que le "quedan" las cria- \\
& turas "balbuciendo", porque no lo \\
& acaban de dar a entender, que eso \\
& quiere decir "balbutir", que es el \\
& hablar de los niños, que es no acertar \\
& a decir y dar a entender qué hay que \\
& decir (CE, prosa, 7, pp. 462-463).
\end{tabular}

nadie dice//aquí pasaste (vv. 2-3) decid si por vosotros ha pasado ( $C E$, poesía, 4, v. 5 ).

pasó por estos sotos ( $C E$, poesía, 5 , v. 2).

desperseveran de morir (v. 5)

Mas ¿cómo perseveras, ;oh vida!, no viviendo donde vives ( $C E$, poesía, 8 , vv. 1-2).

se dolerían para desdoler/ llagan su pura vez/alma vacía/ (vv. 7-8)

y todos más me llagan ( $C E$, poesía, 7, v. 3).

¿dónde pagás los sueldos del amor? 32 (v. 16)

No puede dejar de desear el alma enamorada la paga y salario de su amor (CE, prosa, 9, p. 466).

En una primera aproximación, las fórmulas gelmaneanas parecen situarse en la prolongación directa de la escritura sanjuanista. La poesía de Gelman prolonga la del santo en la medida en que le permite desarrollar una retórica del dolor, o según la expresión de Gomes, un "expresionismo patológico". Este discurso se busca a sí mismo, nunca adecuado a su fin, es un "balbucear". En cambio, Gelman niega la realidad de la presencia del TÚ: "nadie dice/aquí pasaste". La ausencia parece sin remedio. Sólo quedan las "recordaciones", los "pedazos del hablar" (vv. 10-11). El intertexto sanjuanista sufre una inversión semántica completa. La incomprensible obstinación en vivir (san Juan) se convierte en un deseo impotente de morir (Gelman, v. 5). El alma ya no espera "la paga y salario de su amor", sino que le toca a ella pagar "los sueldos" (v. 16) ${ }^{33}$.

32 Véase, también, "La muerte rápida es castigo muy leve para los impíos. Morirás exilado, errante, lejos del suelo natal. Tal es el salario que un impío merece" (Eurípides, citado en el epígrafe de Salarios del impio y otros poemas, Visor, Madrid, 1998, las cursivas son mías).

${ }^{33}$ El sujeto de "pagás" es ambiguo, pero lo más lógico es considerar que el Vos es el alma apostrofada en el verso 14 . 
Este alejamiento del espíritu del Cántico espiritual se ve reforzado por otro elemento. Véase la última estrofa del poema XVIII:

en representación de la ternura/

alma a quien todo un hijo pena ha sido/

¿dónde almarás con más amor? / o sea/

¿dónde pagás los sueldos del amor?

(vv. 13-16).

El segundo verso es una cita casi literal de un verso de Quevedo, sacado del famoso soneto: "Amor constante más allá de la muerte"34. Citamos las dos últimas estrofas de este soneto:
Alma a quien todo un dios prisión ha sido,
Venas que humor a tanto fuego han dado,
Medulas que han gloriosamente ardido,
Su cuerpo dejará, no su cuidado;
Serán ceniza, mas tendrá sentido;
Polvo serán, mas polvo enamorado ${ }^{35}$.

Como se puede observar, la sustitución es doble: no sólo "dios" se transforma en "hijo", sino que también la "prisión" se convierte en "pena". La fe ciega de los místicos del siglo xvı da paso al desengaño barroco, pero sin que permanezca la afirmación de la vida ultraterrena.

El motivo sanjuanista del salario del amor (canción 9) se encuentra de nuevo al principio del poema XIX, que prosigue el enlace con fragmentos de versos y comentarios de la canción 10 del Cántico espiritual:

\begin{tabular}{lc}
\hline \multicolumn{1}{c}{ Poema XIX (Gelmam) } & \multicolumn{1}{c}{ Cántico espiritual } \\
\hline $\begin{array}{c}\text { ¿qué otro trabajo tenés/amor/sino } \\
\text { amar?/... }\end{array}$ & $\begin{array}{l}\text { el alma no espera el fin de su trabajo, } \\
\text { sino el fin de su obra; porque su obra } \\
\text { es amar ( } C E, \text { prosa, } 9, \text { p. 467). }\end{array}$ \\
$\ldots$ ¿.mirando con ojos del alma? & Y véante mis ojos ( $C E$, poesía, 10, v. 3). \\
& $\begin{array}{l}\text { Esto es, véate yo cara a cara con los } \\
\text { ojos de mi alma }(C E, \text { prosa, 10, p. 468). }\end{array}$ \\
\hline
\end{tabular}

\footnotetext{
34 NÉstor Ponce ya ha analizado la reescritura de este mismo soneto en otro poema de Juan Gelman (op. cit.).

35 Francisco de Quevedo, Poesia varia, ed. J. O. Crosby, Gátedra, Madrid, 1987, p. 255; las cursivas son mías.
} 


\begin{tabular}{ll}
\hline \multicolumn{1}{c}{ Poema XIX(Gelman) } & \multicolumn{1}{c}{ Cántico espiritual } \\
\hline $\begin{array}{l}\text { para ver lo que amás? / claceración } \\
\text { o brillo/o bestia de dolor? ¿o lumbre } \\
\text { que ilumina una cuna de esperar? }\end{array}$ & pues eres lumbre de ellos \\
\hline
\end{tabular}

La visión beatífica ansiada por los místicos toma en Gelman una resonancia dolorosa. Aunque deseada, esta visión del hijo podría significar un dolor intolerable al mismo tiempo que el final de una pesadilla: si se considera el post scriptum del poemario, Gelman desea ver el cadáver de su hijo para llegar a una verdad tangible que permita el paso hacia una denuncia, por un lado, y hacia un verdadero duelo personal, por otro. De ahí que el tema de la visión, esperanza gozosa en san Juan, se vincule en Gelman con un dolor agudo: "laceración", "bestia de dolor". La visión no revela ningún horizonte que permita dar sentido al dolor, sino que constituye la posible (y terrible) encarnación definitiva de éste.

La expresión de ese dolor alcanza su paroxismo en el poema XX, que retoma el comentario de la canción 12, en la que el santo explica hasta qué punto la visión de Dios es inaguantable para el alma y el cuerpo:

\begin{tabular}{ll}
\hline \multicolumn{1}{c}{ Poema XX(Gelman) } & \multicolumn{1}{c}{ Cántico espiritual } \\
\hline todo el día/todos los días/arde & Porque a veces es tan grande el tor- \\
helado/como si los huesos se & mento que se siente en las semejantes \\
descoyuntaran/ (v. 5-7) & visitas de arrobamientos, que no hay \\
& tormento que asi descoyuntase los huesos \\
& y ponga en estrecho al natural, tanto \\
& que, si no proveyese Dios, se acabaría \\
& la vida ( $C E$, prosa, 12, p. 473).
\end{tabular}

Estos versos constituyen el punto álgido de la reescritura sanjuanista a la que se dedica Gelman en Carta abierta. En efecto, no es posible ir más allá de ese dolor. En san Juan, el verso ("Apártalos, Amado"), cuyo comentario aparece en filigrana en Gelman, precede directamente el éxtasis del alma ("que voy de vuelo") que da lugar a una visión beatífica de la totalidad del $\operatorname{cosmos}^{36}$, imagen del "desposorio

36 Véanse las estrofas 13 y 14: "Mi Amado, las montañas, / los valles solitarios nemorosos, / las ínsulas extrañas...". 
espiritual"37. En el poema de Gelman también, este punto culminante del dolor precede un descubrimiento fundamental:

$$
\begin{aligned}
& \text {../o palabra muda } \\
& \text { donde procuro andar contra la muerte/ } \\
& \text { alma que musicás música que } \\
& \text { toda la anchura de la mundo a penas } \\
& \text { pasa/rota/tristea alrededor } \\
& \text { de lo que me dejaste/noche a pie }
\end{aligned}
$$

(Poema XX, vv. 7-12).

No se trata, como en san Juan, de un éxtasis de amor humanodivino aunque se evoque "toda la anchura de la mundo". Pero el poeta parece haber encontrado el discurso adecuado, superando las alternativas binarias con las cuales se abría el poemario ("hablarte o deshablarte"), en una expresión oximorónica que concentra todo el proyecto de Carta abierta: "palabra muda donde procuro andar contra la muerte". Sin embargo, más allá de la afirmación de la validez de semejante gesto poético, no hay ninguna exaltación: sólo queda la tristeza de un mundo desencantado, "triste". Los "levantes de la aurora" no se dejan vislumbrar en un mundo "roto", hundido en la "noche", en la que a pesar de todo resuena una "música".

Los últimos poemas de la colección (XXI-XXV) vuelven a profundizar en las imágenes dolorosas de la desaparición: “¿nadie tortura tu blancor?" (poema XXI), "nave que se detiene en pleno mar//como puerto donde cargar su nunca" (poema XXIII). El poeta prosigue su camino interior y su tarea creadora ("la alma camina//dentro de sí/y ojalá resplandezcan// piedras que pulo con tu respirar", poema XXIV), que son la única manera de arrancar al hijo del olvido, es decir, de la muerte: "te destrabajo de la muerte como//puedo/pobre de vos/" (XXIV). Este mismo poema se cierra con una nota esperanzadora: la acción generosa del VOS ("compañero//de los creídos/ de los afligidos") no ha sido vana ya que "por tu pobrear se alzan los soles", "fuera// ternura que estuvieras/vivo/sos".

En el último poema (XXV) se alcanza la expresión más despojada de la "indagación en el dolor" que constituye los textos de Carta abier$t a$. Después de haber buscado un lenguaje adecuado para su propio dolor, retomando ecos de la tortura del alma apartada de Dios pero

${ }^{37}$ Cf:, por ejemplo, el comentario de Domrngo YNDURárn: "En estas dos estrofas, pues, se da la mera enumeración de la maravilla del universo: el Amado, su presencia y unión, hace que todo el universo se integre en armonía y belleza; el circuito espiritual se cierra y la belleza que desciende de Dios a las criaturas y de éstas al Creador se hace evidente, no necesita explicación, y por ello se nombra, no es menester articulaciones que organicen los datos inmediatos de la conciencia" (en su ed. cit. a san Juan de la Cruz, Poesias, p. 93). 
quedándose en el umbral del éxtasis sin franquearlo, la voz de Gelman se desnuda de todo narcisismo, de toda consideración acerca de su propio dolor o de su escritura, para reconcentrar la palabra poética en el destinatario. En efecto, este poema es el único en el cual el VOS esté omnipresente, sin ninguna forma en primera persona ${ }^{38}$. Los dos últimos versos no sellan el dolor con ningún cuño consolador:

$$
\begin{aligned}
& \text {.../ ¿̧hijás?/ } \\
& \text { ¿incansable de puro sufrir? }
\end{aligned}
$$

Aunque ciertos versos parecen sugerirlo, pero siempre en tono interrogativo ${ }^{39}$, el dolor no abre a ninguna experiencia que permita trascenderlo: el poeta está encerrado sin remedio en esa "doloración de vos como clausura" (poema XV). La clausura remite tanto al discurso del religioso carmelita como a la prisión quevediana (o vallejiana). Paralelamente a la intertextualidad "fuerte" que inscribe los textos de san Juan de la Cruz y Quevedo en el poema de Gelman, nos parece que también se puede evocar una intertextualidad "débil" con la poesía de Vallejo por ese mismo énfasis en el dolor que apunta a una mística sin otro éxtasis que el de una pena sin salvación ${ }^{40}$.

Esta pena desnuda es la que se expresa en los cinco últimos poemas de Carta abierta en los cuales hemos buscado en balde huellas sanjuanistas. El intertexto sanjuanista se interrumpe, repitámoslo, en el momento en que se empieza a describir la unión entre Dios y el alma. Muy lejos de la consonancia entre amor divino y humano que se halla, por ejemplo, en ciertos textos de Ernesto Cardenal caracterizados por una intertextualidad fuerte con la poesía del santo ${ }^{41}$, esa unión

${ }^{38}$ Salvo un nosotros (“¿rostro es el tuyo?/ ¿que no vemos?") que abre su interrogación angustiada al conjunto de los lectores.

39 Por ejemplo, el poema XXII: “¿leche//pensás que la dolor lechara como// gracia volando/ derramada/ como// amor de quien se ausenta mucho?".

${ }^{40} \mathrm{Al}$ comentar los primeros versos de "Heraldos negros", JEAn Franco afirma: "El cogito cartesiano se encuentra aquí invertido, sufro y soy pero no sé. El ser se comprueba por los golpes y las caídas... cuyas causas son conjeturales... El hombre sufre todas las culpas y los castigos de la tradición religiosa occidental sin la certidumbre de la fe" ("La temática de Los heraldos negros a los Poemas póstumos", en César Vallejo, Obra poética, coord. A. Ferrari, UNESCO-Colección Archivos, Buenos Aires-Bogotá-MéxicoMadrid, 1988, p. 578). En la misma perspectiva se puede añadir el comentario de JULio ORTEGA: "El lenguaje no es la "casa del ser» (como en el idealismo heideggeriano) sino el espacio del desamparo. Si el carácter inefable de la tradición mística (y de la lírica) implica un discurso de la plenitud ( "un no sé qué que quedan balbuciendo", etc.), el «yo no sé» vallejiano implica un discurso de la carencia, un balbuceo que verifica la erosión del edificio de la tradición. En esta fisura nombra Vallejo" ("La hermenéutica vallejiana y el hablar materno", en ibid., p. 607). Para GoMes, Gelman es aún más radical que Vallejo ya que "no hay el «cáliz» redentor vallejiano" ( op. cit., p. 658).

41 Véase, al respecto, Luce López-BARAlt, "El cántico espiritual de Ernesto Cardenal. Hacia la fundación de la literatura mística hispanoamericana”, en El sol a 
no existe en Gelman, aunque subsistan el amor y la memoria, las dos fuentes del dolor en un mundo destrozado por la violencia.

La reescritura gelmaneana del Cántico espiritualsorprende por su fidelidad y su libertad: su fidelidad, porque Gelman se ciñe a la progresión de un discurso ajeno que rige de manera soterrada la ordenación del poemario; su libertad, porque destruye las barreras entre las épocas, los registros, los géneros y dota de una nueva significación un intertexto que, a su vez, da a la poesía de Gelman una hondura y una universalidad insospechadas. Carta abierta constituye pues un hito fundamental en la trayectoria de Juan Gelman que desplegará nuevas modalidades intertextuales en poemarios posteriores en los cuales los escritos de los místicos castellanos seguirán muy presentes pero, esta vez, de manera explícita ${ }^{42}$.

En este sentido, hay una evolución muy clara de Carta abierta a $\mathrm{Ci}$ tas y Comentarios ${ }^{43}$, libro doble en el que Gelman reescribe, explícitamente esta vez, a los grandes místicos (de los profetas bíblicos a santa Teresa, pasando por Hadewijch y san Juan de la Cruz) y a los letristas de tango. Por un lado, Gelman ahonda, de manera más sistemática y explícita, en la práctica intertextual cuya significación se focaliza en la expresión híbrida de una "visión exiliar" que el poeta comparte con los místicos y los letristas de tango. Al inscribir, en el seno de su propio lenguaje poético, los ecos de una poesía popular por antonomasia (el tango) y el discurso místico (poesía y prosa), Gelman acentúa su gusto por desplazar sorprendentemente los límites genéricos. Por otro lado, Gelman atenúa el dramatismo de Carta abierta en numerosos poemas en los que no sólo reescribe las primicias angustiadas del desposorio espiritual cantado en el Cántico, sino que también alude o cita fragmentos de Llama de amor viva ${ }^{44}$, para evocar su reencuentro con la patria a la vez perdida y siempre presente ${ }^{45}$.

Geneviève Fabry

Université Catholique de Louvain

medianoche. La experiencia mística: tradición y actualidad, eds. L. López-Baralt y L. Piera, Trotta, Madrid, 1996, p. 25.

42 Véase, al respecto, G. Fabry, "Les citations de saint Jean de la Croix dans la poésie de Juan Gelman: typologie et effets de sens", en Création, sens, éthique: la triangulation des enjeux littéraires, études rassemblées et présentées par M. Watthee-Delmotte, Lettres Romanes, Louvain-la-Neuve, 2000, pp. 77-91.

43 La noción de evolución se basa en las fechas de publicación. Habría que matizarla aduciendo las informaciones relativas a las fechas de redacción mencionadas en de palabra: Carta abierta (enero, 1980), Comentarios (1978-1979), Citas (noviembrediciembre, 1979) (cfi de palabra, pp. 125, 185, 255).

44 Por ejemplo, en los Comentarios XXII y XXV.

45 Cf. la dedicatoria "a mi país" en Citas y Comentarios. Véase, al respecto, el artículo de María Rosa Olivera-Williams, "Citas y Comentarios de Juan Gelman o la (re) creación amorosa de la patria en el exilio", Inti, 1989, núms. 29/30, 79-88. 
